Canavarro, M. C. \& Pires, R. S. A. (2011). The Impact of Gynecological Cancer on Reproductive Issues and Pregnancy:

Psychological Implications. Current Women`s Health Reviews, 7(4), 367-378.

Link: http://www.benthamdirect.org/pages/content.php?CWHR/2011/00000007/00000004/D0011W.SGM

The final publication is available at $\underline{w w w . b e n t h a m s c i e n c e . c o m}$

\title{
The Impact Of Gynecological Cancer On Reproductive Issues And Pregnancy: Psychological Implications
}

\author{
Maria Cristina Cruz Sousa Portocarrero Canavarro ${ }^{1,2}$ \\ \& \\ Raquel Sofia Antunes Pires 1,2,3
}

\begin{abstract}
${ }^{1}$ Faculty of Psychology and Educational Sciences, University of Coimbra, PORTUGAL; ${ }^{2}$ Psychological Intervention Unit of the Maternity Doctor Daniel de Matos, Hospitais da Universidade de Coimbra, PORTUGAL; ${ }^{3}$ PhD Student (FCT $\underline{\mathrm{SFRH} / \mathrm{BD} / 63949 / 2009)}$
\end{abstract}

Full address for correspondence:

Maria Cristina Canavarro

Faculdade de Psicologia e Ciências da Educação da Universidade de Coimbra

Rua do Colégio Novo, Apartado 6153, 3001-802 Coimbra, Portugal

Tel:(+351) 239851450

Fax: (+351) 239851462

Email: mccanavarro@fpce.uc.pt

\begin{abstract}
Gynecological cancer is the fourth most common form of cancer among women. Over the past few decades, the growing number of survivors has been forced to cope with the consequences of the disease. Of these consequences, the impact of cancer on reproduction has been receiving increasing attention. Research shows that the health care of these women poses challenges other than medical ones. Although the inclusion of psychologists in health care teams has been particularly valued, studies focusing on the psychological implications of the impact of gynecological cancer on reproduction are scarce. Therefore, the first aim of this review is to critically reflect on the psychological implications of infertility, decision-making regarding childbirth, and pregnancy in the context of gynecological cancer. The second purpose of this review is to provide practice guidelines that account for the specificities and demands of these patients. Our findings suggest that gynecological cancer entails specific emotional and decisional challenges regarding reproductive issues, highlighting the importance of specialized psychological interventions with patients and their families. Providing emotional support and education about sexual and reproductive difficulties, supporting decision-making about fertility preservation and childbirth, promoting adjustment to cancer during pregnancy and supporting transition to motherhood are the main areas of intervention suggested. A
\end{abstract}


multidisciplinary treatment approach also seems to be essential, and the role of psychological teams can be particularly important because these professionals may enlighten and encourage skills in other health care providers.

Key-words: decision-making, gynecological cancer, infertility, pregnancy, psychological impact, women’s health.

\section{INTRODUCTION}

Gynecological cancer - encompassing carcinomas of the ovaries, cervix, endometrial tissue, fallopian tubes, vagina and vulva [1] - is the fourth most common form of cancer among women [2,3]. These malignancies can occur at different times of a woman's life cycle, including the reproductive age $[1,4,5]$.

Since the 1970s, the death rates of women with gynecological cancer have significantly declined. As a result, there has been a growing number of survivors who are forced to cope with the consequences of the disease and its treatments [6]. Among these consequences, infertility has been receiving a large amount of attention over the past few decades [4]. It is estimated that $35 \%$ of women undergoing chemotherapy or pelvic radiation during their reproductive years experience subsequent infecundity [7]. Therefore, fertility preservation in cancer patients and infertility treatments among survivors have been main research topics [8-11].

There have also been important changes in the social role of women in the last few decades that have contributed to the postponement of childbearing. This has led to an increase in cancer survivors who still want to become pregnant [12-14] and also the number of cases diagnosed during pregnancy $[1,3]$. Several studies have shown the specific difficulties that this cooccurrence poses in terms of cancer diagnosis, treatment, and prognosis [1].

Consequently, the interface between gynecological cancer and reproduction has become a current problem, which is associated with specific medical and psychosocial challenges [13-19]. The majority of studies conclude that the management of reproductive issues in patients - including pregnant ones - and survivors requires a multidisciplinary approach. Although the inclusion of psychologists in health care teams has been particularly valued in this field [8, 15, 20-25], studies focusing on the psychological implications of the impact of gynecological cancer on reproduction are scarce. As such, psychological intervention on reproduction in the context of cancer constitutes a less developed area in women's health care.

The aim of this review is to critically reflect on the psychological impact of the interface between gynecological cancer and reproductive issues in general, and pregnancy in particular, while providing some guidelines for practice. Specific objectives include the following: 1) to identify the psychological implications of the impact of gynecological cancer on the reproductive pathway of women in terms of infertility and decision-making regarding childbirth, 2) to analyze the psychological impact of gynecological cancer diagnosed during pregnancy, and 3) to critically review psychological interventions in this context. To achieve this, a brief literature review on the medical impact of gynecological cancer on women's reproduction is discussed. Next, a critical reflection that focuses on the psychological aspects involved is offered, including the presentation of some considerations for practice.

\section{THE MEDICAL IMPACT OF CANCER ON REPRODUCTION}

Gynecological cancer treatment is often quite morbid and may include multiple modalities (e.g., surgery, radiation, and chemotherapy). Because the tissues and organs involved are closely connected with a women's reproductive capacity, the disease and its treatments may have an important medical impact on the reproductive pathway. Subsequent fertility capacity may be compromised in these women $[4,8,9,18]$, and pregnancies after cancer should receive special medical attention [10]. The diagnosis of cancer during pregnancy also poses additional challenges for physicians [1].

\section{Fertility capacity after cancer}

In all types of cancer, particularly in gynecological malignancies, questions concerning subsequent fertility pose additional challenges to physicians [8, 25-29]. Surgery, chemotherapy, radiotherapy, or a combination of these is often used to treat cancer patients. The consensus is that these procedures may cause loss of ovarian function $[8,9,18,30]$. Moreover, surgical treatment for gynecological cancer may change a women's reproductive anatomy in a drastic way and can even imply the removal of critical parts of their reproductive system, causing permanent infertility [4].

A few decades ago, this did not prove to be a problem. Most women who had cancer, particularly of the gynecological type, had already birthed children. Currently, however, the incidence of cancer in those who still want to become pregnant is increasing significantly $[13,14,18]$. As a result, over the past few decades, fertility preservation in cancer patients has received considerable attention and been an area of major development. 
A significant number of studies, from 1965 to 2001, show great decreases in fertility disadvantages reported by cancer survivors compared with the general population [8]. Although the preservation of fertility in young gynecological cancer patients still represents a major challenge for oncologists, currently, a cancer diagnosis has quite different implications $[8,10]$. Increases in early detection of most forms of cancer [5, 18], recent developments in surgical techniques, and the currently favored less aggressive management of gynecological cancers have greatly improved the prospects of parenthood after the disease [5, 8]. Choriocarcinoma, germ cell ovarian cancer, and early cases of ovarian invasive and cervical cancer are some examples of gynecological cancers that presently allow for the possibility of undergoing fertility-saving procedures [10, 31, 32]. There have also been important technological developments in fertility preservation and infertility treatment. When preservation of the reproductive organs is not possible, these procedures provide patients with the option of future pregnancies $[5,8,9]$. Surgical and assisted-reproduction innovations, such as embryo, oocyte or ovarian tissue cryopreservation, ovarian transposition, ovarian suppression, apoptotic inhibitors, and the construction of artificial gametes, are some of the main developments in this field [9].

\section{Pregnancies after cancer}

Women who have experienced cancer are commonly advised to wait one or two years after successful treatment before conception [7, 33, 34]. This recommendation is based on the fact that most cancer recidives occur during this period [34]. When comparing survivors who became pregnant with those who did not, research has shown no increase of death rates or higher incidence of metastasis. Furthermore, there seems to be no increased risk of congenital anomalies or genetic cancer vulnerability in children born to cancer survivors. Exceptions were found in children exposed to chemotherapeutic agents during the first trimester of pregnancy and in families with rare inherited cancer syndromes [30, 35-43]. However, pregnancies in survivors are considered to be high-risk pregnancies, due to an increased percentage of preterm births, low birth weight infants, and perinatal loss. These outcomes are more frequent among young women who experience gynecological cancer and subsequent treatments, such as pelvic radiation or uterine exposure to radiotherapy [10, 44-46].

\section{Cancer during pregnancy}

Approximately 1 per 1000 pregnant women develop cancer during pregnancy $[12,15]$, with the most frequent types being uterine, breast and ovary cancer, melanoma, lymphoma and leukemia [12, 20, 47-53]. Among these, breast cancer is the most frequent [53]. Gynecological cancers, such as carcinomas of the uterine cervix, ovary, vulva and fallopian tube also appear, with incidences of 0.24 to 0.45 [49, 54], 0.05 [55], 0.005 [56] and 0.005 [49] per 1000 pregnancies, respectively. This occurrence has increased over the last thirty years [12].

When gynecological cancer is diagnosed during pregnancy, there is always a conflict between optimal maternal therapy and fetal well-being $[1,15]$. The medical challenges that gynecological cancer presents when concomitant with pregnancy lead to its being considered an extremely high-risk pregnancy [21]. This clinical condition also involves important theoretical, ethical and practice dilemmas. Some inherent challenges are unavoidable for physicians in terms of cancer diagnosis, treatment and prognosis.

Some gynecological cancers are asymptomatic, making them difficult to diagnose $[1,26]$. Non-specific symptoms and hematological and biochemical abnormalities are frequently attributed to normal features of pregnancy [15] and are thus often ignored by both patients and physicians $[1,15,20,25]$. Additionally, the effect of cancer diagnostic procedures on the wellbeing of the fetus has not been studied in great detail, and the conclusions of the few studies available are not completely clear regarding this subject [21, 57-62]. Consequently, Singh [15] noted that the diagnostic workup of pregnant women with cancer should limit exposure to ionizing radiation, and that only absolutely necessary radiologic workup is justified. The author explains that ionizing radiation, whether diagnostic or therapeutic, can be harmful to the fetus depending on the dose and gestational age of the fetus. Plain chest X-ray and two-view mammography appear to be safe procedures when appropriate radioprotection is used; however, abdominal plain films, radionuclide isotope scans and tomography scans should be avoided. For imaging of the brain, liver or bones in the context of clinical suspicion for metastases, magnetic resonance imaging has been advocated. Finally, gadolinium should be avoided because evidence exists of its capacity to cross the placenta and to cause fetal abnormalities in rats.

Cancer treatment during pregnancy requires balance between obstetric and oncologic management [21]. The choice of treatment is influenced by the need to provide the best care for the mother, while minimizing the risk to the fetus [15]. Chemotherapy can be administered after the first trimester but not around the time of delivery [25]. When given in the first trimester, chemotherapy can lead to fetal loss, neonatal death, or malformations of the newborn [60]. After this period, the risk of fetal anomalies is low [59]. Intrauterine growth restriction is the predominant effect [1,21]. According to some authors, the last dose of chemotherapy should occur at three weeks before delivery [51]. It should not be given after 35 weeks of gestation, 
because spontaneous delivery may occur [60]. Radiotherapy and hormonal therapy are usually avoided [25], and surgery should be carefully considered on an individual basis depending on the type of cancer [1].

Another crucial question when considering cancer treatment during pregnancy is the initiation time. The possibility of delaying the treatment until fetal maturation must be carefully considered and balanced with the potential effects on the mother's health. This complex decision is influenced by factors such as the clinical stage of the tumor, gestational age, mother and fetus's health status and the ethical, cultural, and religious values of the patient $[1,20,25,61]$.

According to some authors, termination of pregnancy is not beneficial. This scenario is discussed only if the pregnancy postpones the appropriate therapy [25]. Conversely, some authors state that the immunological suppression and high concentrations of growth factors during pregnancy can adversely affect cancer outcomes [15].

As such, the prognosis tends to be worse when compared with that of non-pregnant women with the same conditions [20]. It is also possible that this is due to the advanced clinical stages of cancer in these women [20, 24]. However, these conclusions are not widely agreed upon [28].

We have thus far described the medical challenges posed by the three major areas of reproduction related to cancer that must be taken into account when considering women's health care. Next, we will focus on the psychological implications of these challenges. In relation to fertility capacity and pregnancies after cancer, our critical reflection will focus on the psychological implications of infertility and decision-making about childbirth. Subsequently, the psychological implications of the occurrence of cancer during pregnancy will be analyzed.

\section{PSYCHOLOGICAL IMPLICATIONS}

Some authors have discussed the increased risk posed by gynecological cancer to women's mental health. This impact has been mainly considered in the management of sexual issues during and after the disease [4, 6, 63, 64]. However, the literature about the psychological challenges resulting from the impact of this type of cancer on women's reproduction is limited. There are few available investigations on how cancer survivors cope with the (im)possibility of having children of their own. Specifically, no quantitative research analyzes the way women cope with infertility or with the decision-making process about having or not having a child after the disease $[8,23,33]$. Also, very few studies have assessed the psychological impact of a diagnosis of maternal cancer during pregnancy [21,29]. This literature is reviewed in the following subsections.

\section{Cancer-related infertility}

There is a reasonable amount of information about the importance of parenthood for cancer patients and survivors. Accordingly, studies show that infertility is one of their major concerns [65, 66]. Studies carried out with cancer patients, particularly breast cancer ${ }^{1}$ patients, show that these concerns can determine patients' treatment decisions [14]. Some studies also conclude that most survivors feel healthy enough to be good mothers. Women often believe that their illness experience increases the value they place on family closeness and are particularly distressed about infertility if they were childless before starting treatment. There is also evidence that patients and survivors are not receiving sufficient information about the causes of their difficulty in conception and about the existing options for overcoming or treating it $[35,66]$. The attitudes, emotions, choices and psychosocial consequences that are involved have received less attention from researchers [33, 66, 68]. Similarly, little information is available about specific findings in gynecological cancer patients and survivors [69, 70].

Infertility is emotionally painful even as an isolated health problem [71]. In the context of cancer, the ability to conceive and raise a normal child appears to be a major issue that influences a woman's quality of life $[22,72,73]$. Some studies have shown that cancer-related infertility is a potential cause of distress [68] and long-term depressive symptoms [74]. Repercussions on other aspects of survivors' lives have also been identified. A perceived loss of opportunity for motherhood may be devastating to women's self-esteem and may be potentially damaging to marital or other intimate relationships [68].

To our knowledge, no quantitative research has compared the psychological impact of infertility in survivors and in the cancer-free infertile population. However, some authors hypothesize that infertility poses specific psychosocial needs that are even more devastating to the survivors than to those without a history of cancer. Among other reasons, they mention that women often see infertility as a loss of their femininity and that cancer survivors may already have experienced a deep blow to their self-esteem or sense of attractiveness [33, 68,75]. As survivors often have little information regarding the impact of cancer treatments on their reproductive potential, this problem may come as a surprise to most women $[11,68]$. On the other hand, infertile couples often point out that it is difficult for them to get empathy from family or friends because they have lost a

\footnotetext{
1 The psychological impact of breast cancer has been shown to be very similar to that of gynecologic cancers. The intimate relation of these two forms of cancer with reproduction and motherhood, as well as their impact on self-esteem, sexual-concept and feminine identity are among the main reasons for these similarities $[63,67]$. For this reason, studies carried out among breast cancer patients and survivors were a privileged resource of information for this paper.
} 
potential, rather than an actual, child [76]. In a cancer context, an individual's right to grieve over infertility may be questioned even more [33]. Cancer patients and survivors often feel that their fertility concerns are particularly trivialized. They feel that health professionals, friends and family frequently believe they should be grateful to be alive, and not concerned with subsequent issues (i.e., reproduction) [9, 11]. On this line, infertility after cancer treatments may cause additional psychological stress, feelings of loss of control, depression and low self-esteem [9].

The specific connection between gynecological cancer and feminine identity can intensify these reactions and impair the adjustment to infertility $[26,33,68]$. The gonadal effect of cancer treatments and reproductive system removal are the main causes of the survivors' difficulty to conceive a child. However, other aspects of sexual dysfunction after treatment may also negatively influence this capacity in gynecological cancer survivors $[8,23]$. Among these women, sexual dysfunction can include pain and important changes in the anatomy of the reproductive organs. As a result, this form of cancer often involves profound modifications in body image, sexual self-concept, and sexual desire [8,64]. These health issues significantly impact the quality of life and emotional well-being of gynecological cancer survivors and may influence their difficulty to conceive and subsequent coping ability $[64,69,70]$.

\section{Decision-making about childbirth after cancer}

Despite the great impact imposed by the difficulty of conceiving a biological child on survivors, this is not the only issue involved in deciding whether or not to have children after cancer. As noted by Syse, Kravdal and Tretli [8], psychosocial mechanisms contributing to childbirth after cancer have been largely ignored in the literature. There is no specific research on gynecological cancers in this field. However, a general framework of reproductive decisions and recent developments about general and breast cancer survivors are available. These findings constitute useful guidelines for the comprehension of these mechanisms.

Reproductive decision-making is a highly complex and sensitive process, even among healthy women. As noted by Sherr, Barness and Johnson [77], decision-making depends on the pre-existing views of the information recipient, their desires and wishes, the way the information is presented, the framing of the data, the relative risks, the associated benefits and the personal relevance of these variables. Moreover, the decision to become pregnant is influenced by multiple interacting personal, cultural, and social factors [78, 79]. Among these factors are the individual psychosocial and economic situation, the influence of partners, family, and friends, and the attitudes and practices of their medical providers [11, 80].

In 1988, Michaels proposed a behavioral decision-making approach to examine reproductive decisions [11]. According to this framework, "a decision about whether to have a child at a certain point in time will be determined by the expected value, defined as the degree to which it is perceived to be the optimal way of obtaining desired goals and avoiding undesirable outcomes" [11, p. 284]. Thus, motivations appear to be an important construct in the decisional process of conception [81].

There are both negative and positive motivations associated with the decision to have a child among healthy women. The negative motivations most cited include the following: loss of freedom, interference with career development, financial considerations, possibility of a defective child, fear of responsibility and immaturity. Positive motivations are often related to proof of femininity, fulfillment of the social role as a woman, symbolic immortality, sense of power, and fantasies about the self (e.g., having a perfect love, feeling important) [11].

These motivations are important determinants in the implementation of the desire to have children. However, other factors play an important and direct role. Among them are the occurrence of major life events, the availability of social support and several barriers to motherhood [81]. People are generally subjected to a number of biases when making decisions, and this process is affected by emotional factors and individual coping strategies [77]. With this in mind, it does not seem unreasonable to assume that this decision-making process becomes even more complex in the presence of a serious illness. This often constitutes a major life event and may interfere with an individual's emotional well-being and capacity for decision-making.

In the particular context of cancer survival, the literature shows some specific negative motivations for childbirth, with fears related to the impact of pregnancy on both the woman's and child's health among the most cited $[11,35,66,68,82,83]$. These concerns may be intensified in the case of gynecological cancer, because of the intimate relationship between the involved organs, reproductive capacity, and the unborn child's well-being. Other negative motivations are associated with survivors' ability to be good and present parents, fears of not living to see their children grow up, having diminished energy to cope with the challenges of childrearing, and fears of not being able to be sufficiently resourceful parents [33, 68, 82]. Similarly, fears of being unable to support the family or of unpredictable social or psychological implications for themselves and their children are also mentioned [35, 83]. In Braun, Hasson-Ohayon, Perry, Kaufman and Uziely's research [11], breast cancer survivors, compared with healthy women, reported more negative motivations toward childbirth due to health concerns. Less conservative reasons, such as financial and personal restrictions, fear of responsibility and immaturity, were identified 
among this population. These findings suggest a possible change in life priorities and attitudes as a result of the cancer experience.

Most studies show the increase of value that is placed on children and family life after experiencing a serious illness [35, $66,83]$. Some investigations with the breast cancer population reveal that the illness did not negatively influence couples' planning regarding childbirth [11, 35, 83]. Moreover, this desire may be intensified [33, 82]. Most authors suggest that having survived cancer leads to new symbolic meanings being attached to having a child, such as being normal and capable of producing something beautiful $[35,83]$. Research also shows that breast cancer survivors' partners reported more positive motivations related to immortality [11]. In gynecological cancer patients, it is possible that some of these new symbolic meanings are even more present, due to the specific threat that the disease represents to sexual functioning, reproductive capacity [8, 23], and feminine self-esteem and identity [63].

\section{Cancer during pregnancy}

The psychological implications of cancer occurrence during pregnancy have recently been discussed [21, 22, 29, 84]. There is no specific research about the diagnosis of gynecological cancer during this period. However, it is possible to draw some considerations regarding the specificity assumed for the impact of this type of cancer. In general, the psychological implications of this co-occurrence can be considered according to three broad areas: the meaning of cancer, cancer treatment decisions, and transition to motherhood. A critical analysis of the available literature is presented in the next subsections.

\section{The meaning of cancer during pregnancy}

The diagnosis of cancer is a devastating moment for the individual [4, 63]. Emotions such as shock, disbelief, emotional turmoil [4, 85], sadness [6], anger, anxiety, and guilt are recurrent in response to this event [4, 6, 63]. The diagnosis may interfere with mental and physical abilities and cause severe lifestyle disruptions. Personal, family and social roles, as well as the idiosyncratic belief system, are often affected. Cancer threatens fundamental assumptions about a patient's life, suddenly questioning beliefs about self, the world and relationships [86].

Sometimes, before individuals have had time to work through their feelings of shock and grief, they must begin a treatment plan [4]. Most of them are unprepared to deal with the many side effects of medical treatment and its psychological consequences. They experience heightened anxiety and depression not only at diagnosis, but also at critical points during the disease or treatment [64]. Among gynecological cancer patients, risk factors for maladjustment include treatment characteristics, such as the location of surgery [63, 87]. Radiotherapy, multi-modality treatment [26] and the short- and longterm side effects of treatment also appear to be risk factors [2]. Most studies show specific adverse reactions to physical outcomes in this clinical population, and women sometimes interpret them as a mutilation [63]. Consequences, such as intense depressive symptoms [88], lower quality of life [26, 29], and problems related to sexuality, body image, health perception, physical functioning [87], and intimate relations are the most cited in the literature [29, 64].

As noted by Moorey and Greer [86], and according to Lazarus \& Folkman [89], the individual's adjustment to the disease is a result of the interaction between the perception of the stress involved and the coping strategies available. The patterns of thought, feelings, and behaviors associated with the cognitive appraisals of stressful events compose the style of adjustment the person develops. The way individuals respond to stressful events is determined by the interpretations they make about them [89]. Consequently, some authors state that the stress experienced in cancer conditions depends largely on the specific meaning that the individual attaches to the disease $[63,86]$.

Cancer, in general, often represents an enormous sense of loss. Specifically, it involves loss of autonomy, good health, selfesteem, relationships, employment, social status [63], fertility [26, 28] and mental integrity [22]. However, the threat posed by a cancer diagnosis may be interpreted in several ways by different individuals and under different conditions [63, 86].

Regarding gynecological cancers, its specific characteristics should be taken into account in order to understand the threat that the disease represents for patients as well as their feelings about themselves as women and about childbearing. The uterus, vagina, and ovaries are organs directly connected with the feminine identity [63]. This connection can harm women's sense of self-worth and sexuality, thus affecting their quality of life [4, 87, 90]. Moreover, this impact may be more intense when cancer occurs during pregnancy [22, 29, 91]. As this is a moment of women's life when their female role and disposition to motherhood are even more salient, it is necessary that they adapt to profound changes in sexual and reproductive anatomy and functioning, which can be extremely difficult and may amplify the physical and psychological impact of the disease.

A number of authors assume that being diagnosed with cancer during pregnancy constitutes a dramatic event, which may have a devastating impact on the patients' somatic and psychosocial health. Indeed, this co-occurrence combines two life events that may cause great stress. In these two opposite biopsychosocial processes, women are concomitantly faced with death and life in their own body. It is possible that the threat's perception and the meaning that women attach to the losses associated 
with cancer are more accurate [21, 29, 91, 92]. Firstly, the implications of any serious illness that occurs during pregnancy results from the traumatic impact of the diagnosis. This is a period when women are somatically and psychologically weaker $[21,29]$. Additionally, during pregnancy, women expect a new life to be born, which may lead to a cancer diagnosis being seen as an even more unexpected event. The confrontation with death is probably more salient in a period when the meaning of life is present in all contexts of a woman's life. The stress perceived and the traumatic impact of the diagnosis can be higher under these conditions.

Secondly, the disease doesn't interfere exclusively with the lives of women. Cancer during pregnancy also threatens the life and well-being of their unborn child. It brings additional awareness to women about the possibility of losing their child. In some cases, it may also imply the permanent loss of the possibility of becoming a mother. In addition, this co-occurrence reinforces the negative meaning attributed to the loss of some capacities, abilities and opportunities because women's competencies for motherhood are also at risk [22, 29].

Thirdly, during pregnancy, women's patterns of behavior, their place in society and within the family and their own identity are in transformation [21]. Therefore, it does not seem unreasonable to hypothesize that the impact of a cancer diagnosis may be even greater for the idiosyncratic belief system of these women under these conditions.

Finally, there is also a great stress perceived in association with cancer management when it occurs during pregnancy. This co-occurrence requires a high mobilization of resources and energy to cope with diagnosis and treatment. It occurs at a moment when women's resources to cope with stressful life events may be reduced [22, 29]. It is also possible that women perceive the resources of the care system in dealing with cancer during pregnancy as reduced. This can be explained by the technical and ethical dilemmas posed by the clinical condition and by the lower agreement about how best to manage it. Thus, this reduced individual perception and the care system resources may contribute to appraisal of the available coping strategies insufficient. The consequent lowered perception of control can exacerbate emotional distress [93, 94]. These women can also neglect getting appropriate assistance [95].

\section{Cancer treatment decisions during pregnancy}

Cancer treatment requires some decisions that must be shared between the patient and the medical team [96]. This process has to be quicker when a pregnancy is involved [22, 97].

In order to make decisions in the presence of a serious illness during pregnancy, women need information about all the medical issues involving both the child's health and their own. Available options and possible consequences of each are also important in their decision-making process. Indeed, information is a basic building block for decision-making [97]. However, beyond the necessary and delicate balance between the medical risks and benefits of treatment, other factors need to be considered including the following: patients' life, work responsibilities, family commitments, financial burdens, additional inputs from culture, social norms, and spirituality [98-100].

This process places numerous additional challenges on physicians and patients. Women are characteristically insecure about decisions that have to be made in high-risk pregnancies. They become confused and disorganized at a time when vast amounts of medical information must be comprehended [62]. In cancer situations, the great emotional impact of the diagnosis may significantly reduce patients' ability to understand the information they are given. There is agreement in the literature about the adverse effect that anxiety may have on a person's ability to process, recall, and comprehend information [97]. Additionally, pregnant patients are confronted with suboptimal therapeutic options, none of them being the ideal. They also have to make choices in a short period of time, and ambivalence often marks the decision in these cases [22]. Feelings of doubt, isolation, helplessness, anger and guilt can also surface [22, 29, 62].

In some cases, decisions about the continuation of the pregnancy also have to be made, which probably causes even more difficulties than the treatment choices. The choice of the type or the time of treatment is often perceived as a shared responsibility between physicians and patients. Patients often view this choice as having an indirect effect on their own and their fetus's lives. This is due to all the probabilistic issues involved. On the contrary, although equally shared, couples often perceive the decision of continuing or terminating a pregnancy as a direct determination on the life of the fetus or the woman. Emotional and moral dilemmas are inevitably inherent to this situation, and feelings of guilt, loss, ambivalence, despair and confusion are expectable $[22,29]$.

\section{Transition to motherhood during cancer}

Transition to motherhood is a transformational process that demands a woman to redefine herself and accept the pregnancy and the psychological stress related to it. The establishment of an attachment to the fetus and the adaptation to a relationship with the neonate after parturition are also developmental tasks of this period. It prepares women to adequately and sensitively answer their infants' needs [21, 62, 101, 102]. 
Pregnancy marks the beginning of this elaborated transition. It is usually regarded as a period of great joy and anticipation. However, it is also a time of complex interrelated changes in physiologic equilibrium and interpersonal associations [62, 101 103]. Pregnant women must adapt to an altered physiology, body image, energy level and mood, and changes in interactions with parents, spouse, and other significant individuals. Redefining goals with personal meaning is also referred as a central task in this period of a woman's life. The presence of personal fears, uncertainties, expectations, preoccupations, and ambivalent feelings of vulnerability, incompetence, loneliness, and loss in terms of autonomy, appearance and occupational identity is to be expected [62, 104-106]. As in all important lifecycle events that bring on changes in regular patterns of functioning, pregnancy and the transition to motherhood involve stress even in healthy conditions [62, 107, 108]. It may be an experience marked by overreactions to minor incidents and over-sensibility and a time of risk to heightened anxiety and depression [109, $110]$.

The social and psychological implications of a high-risk pregnancy may be even more significant. Intensive testing, lengthy hospitalizations, prolonged bed rest at home, illness or disability superimposed on pregnancy, realistic fears for personal safety and the life of the unborn child, and a greater risk of being separated from the newborn child pose numerous additional challenges. The normal emotional changes in pregnancy may also be intensified. Several studies show higher levels of stress, depression and anxiety during these pregnancies $[62,88,110]$.

The diagnosis of cancer during pregnancy may exacerbate this risk for maladjustment, which is already higher in high-risk pregnancies. This is due to the severity of this disease, its impact on survival and the invasive and aggressive treatment procedures it encompasses. Moreover, in gynecological cancer cases, the body changes during pregnancy may be intensified by perceived changes due to the presence of the disease [22, 29]. Women's adjustment to changes in their body image related to pregnancy may be difficult [21,62]. Additionally, perceptions about giving birth to a child with the eventuality of not being alive or healthy enough to take care of it may also bring additional feelings of guilt and sadness [29]. As such, it is crucial to recognize that high-risk pregnancies in general, and pregnancies in cancer patients in particular, may be associated with additional difficulties, requiring early mental health intervention $[62,110]$.

Some authors state, based on their clinical experience, that the co-occurrence of cancer and pregnancy might also contribute to the suspension of other psychological processes involved in the transition to motherhood. Tasks such as reorganizing identity, reappraising key relationships, thinking about the viability and normality of the infant, and elaborating thoughts, fantasies, and practical preparations for the newborn appear in the literature as being especially difficult in cases of cancer during pregnancy $[104,111]$. The disinvestment in the unborn child and the inhibition of attachment capacities are some consequences of the suspension of these tasks [29].

However, there is reasonable agreement in the literature about the role of maternal anxiety and depression during pregnancy in an increased risk to a fetus's physical development (e.g., motor activity, intrauterine growth, birth weight, and prematurity) and a child's long-term neurodevelopment [112-117]. For this reason, some authors have called attention to the effect that the distress experienced by a pregnant cancer patient may have [22, 118]. The emotional well-being of the future mother is also essential during pregnancy to facilitate attachment to the newborn and to effectively develop parenting competencies $[119,120]$. Besides the suspension of some normative tasks that may facilitate this attachment during pregnancy, Wendland [29] states that a maternal illness as serious as cancer may interfere with the establishment of early mother-infant interactions at several levels. In addition to the greater risk of prematurity and separation after birth, these women are often in a period of great physical and psychological fatigue, and are, thus, less available for these interactions. This may put the children of these women at risk for additional emotional difficulties and diminished developmental opportunities. Feelings of guilt often appear to be associated with the suspension of these tasks both before and after birth. Some women consider themselves egotistical for having to focus their efforts on their disease and not concentrating only on their child. As noted by Elmberger, Bolund, and Lützén [121], parents are expected to act as the anchor that nurtures and provides emotional security for their children, and the perception of not being able to correspond to this can be disrupting.

Furthermore, aspects such as sexuality [89], relationships with partners [29, 64], motivations, opportunities, contextual constraints and perception of control [86] or mental health [26, 29, 88] are largely influenced by the presence of cancer. These aspects influence, in their turn, the quality of the transition to motherhood [101, 102]. Among them, the presence or absence of perceived control has been highlighted to have a strong impact on individual adaptation and well-being in situations of stress and problem-solving [93, 94, 122]. In a high-risk pregnancy, the sense of control may be clearly impaired, because women's choices regarding pregnancy and childbirth are realistically limited [62]. These women are often confused about what is actually happening with their body, may fear having an abnormal child, and may feel a loss of control over the pregnancy. Accordingly, Lobel, Yali, Zhu, DeVicent and Meyer [95] mention that optimism is a protective factor against distress in highrisk pregnancies. Enhanced perceptions of control may account for a portion of this benefit; that is, optimistic women are more likely to appraise their pregnancy as controllable. This type of appraisal was associated with lower emotional distress. 
However, it is also necessary to give cancer patients realistic information about their clinical condition, which may make this optimistic approach difficult.

\section{PSYCHOLOGICAL INTERVENTION}

The potential value of health psychology interventions has been emphasized in three main areas: 1) promoting health and preventing disease, 2) counseling patients and their families during illness and subsequent treatments and 3) helping physicians and other health care professionals to provide the best possible care for the patient and to facilitate medical procedures through adequate communication [123, 124]. However, specific contributions for the health care of gynecological cancer patients, in terms of reproductive repercussions, are scarcely mentioned in the literature. Nevertheless, the reflections made so far, as well as the integrative approach provided by this paper, contribute to important guidelines for practice in this field. This will be presented next, according to two major areas of contribution: intervention with patients and families and work with health care providers.

\section{Intervention with patients and families}

Prevent and treat sexual and reproductive difficulties among cancer patients and survivors

Sexual and reproductive issues are among the main concerns raised by cancer patients and survivors [74, 125-128]. It is important to take into account the amplified effect that infertility and sexual dysfunction can have on the emotional well-being of these women [23, 66, 68, 74]. The provision of counseling based on emotional support, unconditional acceptance and recognition and validation of their needs and feelings is crucial. Education about diagnosis, treatment, potential late effects, fertility-preserving options and sexual functioning should also become part of their health care. The development of patient education materials and individual, couple or group counseling are adequate in this context [5, 23, 64, 66, 68, 129].

\section{Support survivors' decision-making about childbirth}

Health professionals should consider the importance of the decision-making process about childbirth for cancer survivors. They should be aware of all the concerns, beyond the medical ones, involved in this decision. It is essential that health professionals know the positive and negative motivations of childbirth in this clinical population and that they provide patients with accurate and adequate information on this topic in order to educate them on the decisions they will have to face $[11,35,83]$. As we noted before, some findings suggest the presence of new symbolic and personal meanings to having a child. The decision of having a child based only on personal motivations, such as personal gratification, may put the normative tasks of transition to motherhood at risk. The complexity of this transition requires that parents decentralize themselves so that they are able to invest in personal and relational reorganization [101, 102]. In our opinion, all reproductive decisions that are based on the best interests of the child will certainly be protective against those risks and should be supported by appropriate psychological interventions. Integrating the partners of cancer survivors appears to be useful for the quality of this intervention. The literature also mentions that peer support groups of young survivors may provide an important source of support. In this context, women may be given the opportunity to express their fears, hopes and wishes regarding childbirth [11].

\section{Promote adjustment to cancer during pregnancy}

The psychological impact of the diagnosis of cancer during pregnancy is expressed at several levels, requiring differentiated and specialized psychological care [15, 21, 22, 29]. Emotional support and counseling are useful at the diagnosis stage to avoid the traumatic impact that diagnosis may have. Promoting the ventilation of emotions and the cessation of associated intrusive thoughts may contribute to fostering women's psychological adjustment. Revising life goals and lifestyle and activating support networks are also important $[22,130]$. Important sources of support include the woman's partner, peers and community. All intervention programs should include areas other than the hospital, such as work, household and community [130].

Integrating family, especially women's partners, also seems to be beneficial. Sometimes these agents are not able to provide adequate emotional and instrumental support. Because they are often greatly affected by the situation, it is necessary to value and assess the adjustment difficulties they may be facing $[21,22,62,86]$. Encouraging open communication and the expression of thoughts and feelings about the diagnosis and the clinical situation is important. It is useful to assist partners and family members in dealing with patients' feelings and reactions by listening and responding empathically $[21,62,86,130]$.

Promoting a sense of control may also be particularly important. This can be implemented through the identification of controllable aspects of patients' clinical situation. Finding possible means of monitoring the mother and the unborn child's clinical conditions as well as learning the possible medical response in emergencies and the percentage of controllability of the 
medical procedures used may be useful. Involving patients in active self-monitoring and decision-making is also crucial in order to develop this sense of control [22, 62].

Additionally, in extreme cases, decisions about the continuation or termination of the pregnancy may have to be made, and these couples require special emotional support. There is also a need for a specialized psychological care and a multidisciplinary intervention designed to provide all the information and support they need to comprehend and understand the medical data [22, 29, 97].

\section{Promote and support transition to motherhood during cancer}

There is another area of intervention that should be taken into account in the planning of psychological care of women who experience cancer during pregnancy: promoting and supporting normative tasks of the transition to motherhood. The establishment of an adequate maternal-fetal relationship during pregnancy and after birth has to be stimulated and enhanced. However, the suspension of other developmental tasks during pregnancy must be prevented, and increased emotional support is needed for a successful transition. It is important to allow the evocation and expression of difficulties, feelings of guilt and ambivalence that are usually associated with the cancer occurrence during pregnancy and also to normalize and validate these thoughts and feelings [22]. However, health care providers should not forget that a realistic orientation in the transition to motherhood seems to predict women's adjustment. Churchill and Davis [131] suggest that the principles of cognitive therapy that are consistent with the development of a broad and realistic orientation may be implemented in prenatal and outreach programs as a preventative measure. This orientation requires the consideration of possible positive and negative outcomes of the transitional process to motherhood and the development of action plans to manage those situations.

\section{Work with health care providers \\ Participate in multidisciplinary teams}

The majority of the studies in this area conclude that the management of these patients requires the collaboration of many specialties. This multidisciplinary approach should include physicians, nurses, psychologists, and social workers in order to provide better educational, decisional and emotional support practices for the patients [15, 20-25].

Specific guidelines on how to cope with cancer during pregnancy are available. According to these guidelines, the decisionmaking process when facing cancer treatment choices should receive special attention from multidisciplinary collaborations [132]. Because medical, psychological, religious, social and moral standards are involved, multidisciplinary teams should provide emotional support to these women and actively involve them in their health care decisions [67, 130].

Providing multimodal motherhood education programs in the health services can be especially useful. These programs should aim at preventing the disinvestment in the unborn child as well as in other normative tasks of the transition to motherhood and the cancer treatments. It can also be important to use routine medical procedures during pregnancy to promote the establishment of a mother-infant connection. Touch, guided imagery or ultrasound visualization and childbirth education programs can help the patient to build a more concrete image of her unborn child's development and behavior and promote an affective relationship with him [22, 62]. After birth, it is important that time is devoted to the interaction between mothers and their infants. If this interaction is not possible, photographs and videos can be used to initiate and maintain the parent-child relationship. However, establishing prenatal and postnatal practices that maximize parent-infant interactions and other transitional tasks to motherhood can require changes in hospital routines and policies. It is crucial that hospital practices and health care team behaviors are consistent with this goal. Only a multidisciplinary approach can make the collaboration of all health care providers possible and build the best circumstances to implement them. Moreover, raising the awareness of health professionals regarding the importance of these procedures and involving them in implementation can facilitate the adherence of patients and increase efficiency [62].

\section{Provide education and skills training to health care providers}

The literature often suggests that health care providers may benefit from information and training on how and when to address sexual and fertility issues with their patients $[62,66]$. One way to help physicians is by improving their knowledge and sensitivity concerning the psychological aspects associated with the medical consequences of gynecological cancer. Health care providers need to acknowledge the nuclear role of sexual and reproductive issues in patients' lives, even while they face a life-threatening illness [11]. Improving their communication skills can also be useful in order to improve the quality of patientprovider communication [66].

Cancer during pregnancy also poses additional challenges to health professionals when communicating information about and managing the disease. Firstly, breaking bad news, such as a cancer diagnosis, to a pregnant patient is painful and challenging; thus, good communication skills are required. The diagnosis should be explained by people skilled in 
communication with high biomedical and psychological competency [133, 134]. According to Client-Centered Therapy [135], founded on Humanistic Psychology, communication should be made in a patient-centered way, so that it is perceived as emotional and non-dominant. The term "patient-centered communication" has been used to describe a group of communication strategies and behaviors that promote mutuality, shared understandings, and shared decision-making in health care contexts [136]. Specifically, encouraging patients to express feelings, name and legitimize them, and convey hope can be adequate strategies for cancer situations during pregnancy. It is also important to assess patients' understanding of their situation and their awareness of the prognosis. Providing information about the support services available, documenting it, and offering assistance about relaying information to others can also be useful [22, 134, 137-139]. Secondly, helping pregnant cancer patients in decisional processes about treatment is also a demanding task to health care providers. This should be a shared process [22, 67], and information may be provided gradually, using simple, clear, but not blunt, language [22, 140-143]. It is important for women to have time to reflect, rehearse, and change their decisions. This can help them make good decisions and also have adjusted reactions when they review their decisions [97]. The role of psychologists can be very important in this situation, providing psychoeducation to other health care providers and helping them in the development of adequate communication skills for these specific situations.

\section{CONCLUSION}

The psychological implications of the interface between gynecological cancer and reproduction have to be taken into account in women's health care. In order to do that, it is necessary to consider the complexity of this interface in three main areas: infertility, decision-making about childbirth and cancer diagnosis during pregnancy. It is acknowledged that each of these areas pose additional challenges to gynecologic cancer patients and their health care providers. As a result, research and practical developments in this area should try to structure and assess the efficacy of specialized psychological interventions that meet the demands of these patients. A multidisciplinary treatment approach is also essential, and the role of psychological teams is particularly important because these professionals may educate and foster useful skills in other health care providers.

\section{REFERENCES}

[1] Sivanesaratnam V. Gynaecological malignancies in pregnancy. Rev Gynaecol Pract. 2004; 4: 162-8.

[2] Anderson B, Lutgendorf S. Quality of life in gynecologic cancer survivors. CA Cancer J Clin 1997; 47: 218-25.

[3] Janni W, Gember B, Bergauer F, Rack B, Sommer B, Friese K. Treatment of pregnancy associated gynaecological malignancies. Zentralbl Gynakol 2006; 128: 129-34.

[4] Ezzel PS. Managing the effects of gynecologic cancer treatment on quality of life and sexuality. J Gynecol Oncol Nurs 1996; n.p.

[5] Querleu D. Preservation of fertility in gynecologic cancers. Bull Cancer 2008; 95: 487-94.

[6] Carpenter KM, Andersen BL. Psychological and sexual aspects of gynecologic cancer. Glob Libr Women's Med 2008: Available from: http://www.glowm.com/?p=glowm.cml/section_view\&articleid=276.

[7] Meirow D, Nugent D. The effects of radiotherapy and chemotherapy on female reproduction. Hum Reprod 2001; 7: $535-43$.

[8] Syse A, Kravdal O, Tretli S. Parenthood after cancer: a population-based study. Psychooncology 2007; 16: 920-7.

[9] Maltaris T, Seufert R, Fischl F, et al. The effect of cancer treatment on female fertility and strategies for preserving fertility. Eur J Obstet Gynecol Reprod Biol 2007; 130: 148-55.

[10] Magelssen H, Melve KK, Skjaerven R, Fossa SD. Parenthood probability and pregnancy outcome in patients with cancer diagnosis during adolescence and young adulthood. Hum Reprod 2008; 23: 178-86.

[11] Braun M, Hasson-Ohayon I, Perry S, Kaufman B, Uziely B. Motivation for giving birth after breast cancer. Psychooncology 2005; 296: 282-96. 
[12] Antonelli NM, Dotter DJ, Katz VL, Kuller JA. Cancer in pregnancy: a review of the literature, Parts I \& II. Obstet Gynecol Surv 1996; 51: 125-42.

[13] Blatt J. Pregnancy outcome in long-term survivors of childhood cancer. Med Pediatr Oncol 1999; 33: 29-33.

[14] Simon B. Lee SJ, Partridge AH, Runowicz CD. Preserving fertility after cancer. CA Cancer J Clin 2005; 55: 211-28.

[15] Singh G. Cancer in pregnancy. Indian J Surg 2009; 71: 374-9.

[16] Goldhirsch A, Gelber RD. Life with consequences of breast cancer: pregnancy during and after endocrine therapies. The Breast 2004; 13: 443-5.

[17] Schedin P. Pregnancy-associated breast cancer and metastasis. Nat Rev Cancer 2006; 6: 281-91.

[18] Silva-Filho AL, Carmo AGL, Athayde RS, et al. Safe fertility-peservating managment in gynecological malignancies. Arch Gynecol Obstet 2007; 275: 321-30.

[19] Smith LH, Dalrymple JL, Leiserowitz GS, Danielsen B, Gilbert WM. Obstetrical deliveries associated with maternal malignancy in California, 1992 through 1997. Am J Obstet Gynecol 2001; 184: 1504-12.

[20] Teran-Porcayo M, Castillo-Rangel A, Barrera-Lopez N, Zeichner-Gancz I. Cancer during pregnancy: 10-year experience at a regional cancer reference center in Mexico. Med Oncol 2008; 25: 50-3.

[21] Schmitt F, Jyrkkio F, Tamminen T, Piha J. Cancer during pregnancy: two case studies. Infant Ment Health J 2010; 31 : $71-93$.

[22] Alder J, Bitzer J, Brédart A. Prise en charge psycho-oncologique de la jeune femme encreinte confronteé au cancer Psycho-oncological care for young women facing cancer and pregnancy. Psychooncology 2009; 3: 81-7.

[23] Schover LR. Reproductive complications and sexual dysfunction in the cancer patient. In: Chang AE, Ganz PA, Hayes DF, et al., Eds. Oncology: An evidence-based approach. New York: Springer. 2006; pp. 1589-609.

[24] Singh D, Silverman P. Management of the pregnant cancer patient. In: Chang AE, Ganz PA, Hayes DF, et al., Eds. Oncology: An evidence-based approach. New York: Springer. 2006; pp. 1747-59.

[25] Vinatier E, Merlot B, Poncelet E, Collinet P, Vinatier D. Breast cancer during pregnancy. Eur J Obstet Gynecol Reprod Biol 2009; 147: 9-14.

[26] Pearman T. Quality of life and psychosocial adjustment in gynecologic cancer survivors. Health Qual Life Outocomes 2003; $1: 33-9$.

[27] Meistrich ML, Vassilopoulou-Sellin R, Lipshultz LI. Gonadal dysfunction. In: Devita VT, Hellman S, Rosenberg SA. Cancer: Principles and practice of oncology. 5th edition. Philadelphia: Lippincott-Raven. 1997; pp. 2758-73.

[28] Saunders CM, Baum M. Breast cancer and pregnancy: a review. J R Soc Med 1993; 86: 162-5.

[29] Wendland J. Impact d'un diagnostic de cancer maternele pendant la grossesse sur les interactions précoces parent-bébé Impact of the diagnosis of maternal cancer during pregnancy on early parent-infant interaction. Psychooncology 2009; 3: 88-93.

[30] Averette HE, Boike GM, Jarrell MA. Effects of cancer chemotherapy on gonadal function and reproductive capacity. CA Cancer J Clin 1990; 40: 199-209.

[31] Farthing A. Conserving fertility in the management of gynaecological cancers. Br J Obstet Gynaecol 2006; $113: 129-34$. 
[32] Shepherd JH, Spences C, Herod J, Ind TE. Radical vaginal trachelectomy as a fertility-sparing procedures in women with early-stage cervical cancer: cumulative pregnancy rate in a series of 123 women. Br J Obstet Gynaecol 2006; 113: 719-24.

[33] Schover LR. Psychosocial aspects of infertility and decisions about reproduction in young cancer survivors: a review. Med Pediatr Oncol 1999; 33: 53-9.

[34] Dow KH, Harris JR, Roy C. Pregnancy after breast-conserving surgery and radiation therapy for breast cancer. J Nati Cancer Inst Monogr 1999; 16: 131-7.

[35] Dow KH. Having children after breast cancer. Cancer Pract 1994; 2: 407-13.

[36] Dow KH. Pregnancy and breast cancer. J Obstet Gynecol Neonatal Nurs 2000; 29: 634-40.

[37] Velentgas P, Daling JR, Malone KE, Weiss NS, Williams MA, Self SG, Mueller BA. Pregnancy after breast carcinoma: outcomes and influence on mortality. Cancer 1999; 85: 2424-32.

[38] Weisz B, Schiff E, Lishner M. Cancer in pregnancy: maternal and fetal implications. Hum Reprod Update 2001; 7: 38493.

[39] Von Schoultz E, Johansson H, Wilking N, Rutqvist LE. Influence of prior and subsequent pregnancy on breast cancer prognosis. J Clin Oncol 1995; 13: 430-4.

[40] Surbone A, Petrek JA. Childbearing issues in breast carcinoma survivors. Cancer 1997; 79: 1271-8.

[41] Bryne J, Rasmussen SA, Steinhorn SC, et al. Genetic disease if offspring of long-term survivors of childhood and adolescent cancer. Am J Hum Genet 1998; 62: 45-52.

[42] Kravdal O. Children, family and cancer survival in Norway. Int J Cancer 2003; 105: 261-6.

[43] Sankila R, Heinavaara S, Hakulinen T. Survival of breast cancer patients after subsequent term pregnancy: 'healthy mother effect'. Am J Obstet Gynecol 1994; 170: 818-23.

[44] Brierley JD, Rathmell AJ, Gospodarowicz MK, et al. Late effects of treatment for early-stage Hodghin's disease. Br J Cancer 1998; 77: 1300-10.

[45] Critchley HO, Bath LE, Wallace WH. Radiation damage to the uterus: review of the effects of treatment of childhood cancer. Hum Fertil 2002; 5: 61-6.

[46] Green DM, Whitton JA, Stovall M et al. Pregnancy outcome of female survivors of childhood cancer: a report from the Childhood Cancer Survivor Study. Am J Obstet Gynecol 2002; 187: 1070-80.

[47] Chelghoum Y, Vey N, Raffoux E, et al. Acute leukemia during pregnancy: a report on 37 patients and a review of the literature. Cancer 2005; 104: 110-7.

[48] Daryanani D, Plukker JT, De Hullu JA, Kuiper H, Nap RE, Hoekstra HJ. Pregnancy and early-stage melanoma. Cancer 2003; 97: 2248-53.

[49] Hackel L, Ruble D. Changes in the marital relationship after the first infant is born: predicting the impact of expectancy disconfirmation. J Pers Soc Psychol 1992; 62: 944-57.

[50] Janov AJ,Anderson J,Cella DF, et al. Pregnancy outcome in survivors of advanced Hodgkin's disease. Cancer 1992; 70: $688-92$.

[51] Loibl S, von Minckwitz G, Gwyn K, et al. Breast carcinoma during pregnancy. International recommendations from an expert meeting. Cancer 2005; 15: 237-46. 
[52] Nisker JA, Shubat M. Stage 1b cervical carcinoma and Pregnancy. Obstet Gynecol Surv 1995; 50: 228-38

[53] Shivvers SA, Miller DS. Preinvasive and invasive breast and cervical cancer prior to or during pregnancy. Clin Perinatol 1997; 24: 369-89.

[54] Sivanesaratnam V. Malignant tumours complicating pregnancy. In: Ratnam SS, Bhasker RK, Arulkumaran S, Ed. Obstetrics and gynaecology for postgraduate. Chennai: Orient Longman. 1993; pp. 73-89.

[55] Sivanesaratnam V. Ovarian malignancy in pregnancy. J Obstet Gynaecol Res 1998; 24: 46-9.

[56] Sivanesaratnam V, Pathamanathan R. Carcinoma of the vulva in pregnancy, a rare occurrence Asia-Oceania. J Obstet Gynaecol 1990; 16: 207-10

[57] Ahn BY, Kim HH, Moon WK, et al. Pregnancy and lactation associated breast cancer: mammographic and sonographic findings. J Ultrasound Med 2003; 22: 491-7.

[58] Liberman L, Giess C, Dershaw DD, Deutch BM, Petrek JA. Imaging of pregnancy associated breast cancer. Radiology 1994; 191: 245-8.

[59] Gwyn K. Children exposed to chemotherapy in utero. J Natl Cancer Inst Monogr 2005; 34: 69-71.

[60] Cardonick E, Iacobucci A. The use of chemotherapy during human pregnancy. The Lancet Oncol 2004; 5: $283-91$.

[61] Oduncu FS, Kimmig R, Hepp H, Emmerich B. Cancer in pregnancy: maternal-fetal conflict. J Cancer Res Clin Oncol 2003; 129: 133-46.

[62] Murphy JM, Robbins D. Psychosocial implications of high-risk pregnancy. In: Knuppel RA, Drukker JE, Eds. High-risk pregnancy: E team approach. 2nd ed. Philadelphia: W. B. Saunders Company. 1993, pp. 244-61.

[63] Doumplis D, Smith JR. Communicating with cancer patients. In: Cockburn J, Pawson ME, Eds. Psychological challenges in obstetrics and gynecology: the clinical management. London: Springer. 2007; pp. 299-306.

[64] Laganá L, Mcgarvey EL, Classen C, Koopman C. Psychosexual Dysfunction Among Gynecological Cancer Survivors. J Clin Psychol 2001; 8: 73-84.

[65] Dunn J, Steginga SK. Young women's experience of breast cancer: defining young and identifying concerns. Psychooncology 2000; 9: 137-46.

[66] Schover LR, Rybichi LA, Martin BA, Bringelsen, KA. Having children after cancer: a pilot survey of survivor's attitudes and experiences. Cancer 1999; 86: 697-709.

[67] Zanetti-Dällenbach R, Tschudin S, Lapaire O, Holzgreve W, Wight E, Bitzer J. Psychological management of pregnancy-related breast cancer. The Breast. 2006; 15: 53-9.

[68] Zebrack BJ, Casillas J, Nohr L, Adams H, Zeltzer LK. Fertility issues for young adult survivors of childhood cancer. Psychooncology 2004; 13: 689-99.

[69] Basen-Engquist K, Bodurka DC. Medical and psychosocial issues in gynecologic cancer survivors. In: Chang AE, Ganz PA, Hayes DF, et al., Eds. Oncology: An evidence-based aproach. New York: Springer. 2006; pp. 1828-34.

[70] Butler L, Banfield V, SveinsonT, Allen K. Conceptualizing sexual health in cancer care. West J Nurs Res 1998; 20(6): 683-99.

[71] Hummer-Burns L. An overview of the psychology of infertility: comprehensive psychological history of infertility. Infertil Reprod Med Clin North Am 1993; 4: 433-54. 
[72] Wenzel L, Dogan-Ates A, Habbal R, et al. Defining and measuring reproductive concerns of female cancer survivors. J Natl Cancer Ins Monogr 2005; 34: 94-8.

[73] Cimprich B, Ronis DL, Martinez-Ramos G. Age at diagnosis and quality of life in breast cancer survivors. Cancer Pract 2002; 10: 85-93.

[74] Gorman JR, Malcarne VL, Roesch AC, Madlensky L, Pierce, JP. Depressive symptoms among young breast cancer survivors: the importance of reproductive concerns. Breast Cancer Res Treat 2010; 123: 477-85.

[75] Schover LR. Sexuality and fertility after cancer. New York: Jonh Wiley \& Sons, Inc 1997.

[76] Zoldbrod AP. Men, women, and infertility: Intervention and treatment strategies. New York: Lexington Books 1993.

[77] Sherr L, Barnes J, Johnson MA. HIV interventions in pregnancy: the views of HIV positive women. Clin Psychol Psychother 2000; 7: 385-93.

[78] Kline A, Strickler J, Kempf J. Factors associated with pregnancy and pregnancy resolution in HIV seropositive women. Soc Sci Med 1995; 40: 1539-47.

[79] Sowell RL, Misener TR. Decisions to have a baby by HIV-infected women. West J Nurs Res 1997; $19: 56-70$.

[80] Bedimo AL, Bessinger R, Kissinger P. Reproductive choices among HIV-positive women. Soc Sci Med 1998; 46: 1719.

[81] Miller WB. Childbearing motivations desires and intentions: a theoretical framework. Genet Soc Gen Psychol Monogr 1994; 120: 225-58.

[82] Schover LR. Motivation for parenthood after cancer: a review. J Natl Cancer Inst Monogr 2005; 34: 2-5.

[83] Siegel K, Gorey E, Gluhoski V. Pregnancy decision making among women previously treated for breast cancer. J Psychosoc Oncol 1997; 15: 27-42.

[84] Boin D, Dauchy S, Flahault C. Devenir une mere malade: entre impact de la maladie et nouages familiaux Becoming a sick mother: the impact of the disease and family knots. Psychooncology 2009; 3: 94-7.

[85] Weisman AD, Worden JW. The existential plight in cancer: Significance of the first 100 days. Int J Psychiatry Med 1976; $7: 1-15$.

[86] Morrey S, Greer S. Cognitive behavior therapy for people with cancer. New York: Oxford University Press 2007.

[87] Lopes HB, Ribeiro JLP, Leal IPL. Estudos sobre qualidade de vida em mulheres submetidas a histerectomia ou anexectomia para tratamento de cancro do colo do útero ou ovário Quality of life in women undergoing hysterectomy or adnexectomy for treatment of cervix or ovarian cancer. Análise Psicológica 1999; 3: 483-97.

[88] Simonelli LE, Fower J, Mazwell GL, Andersen B. Physical sequelae and depressive symptoms in gynecologic cancer survivors: meaning in life as a mediator. Ann Behave Med 2008; 35: 275-84.

[89] Lazarus RS, Folkman S. Stress, appraisal and coping. New York: Springer 1984.

[90] Steninga SK, Dunn J. Women's experiences following treatment for gynecologic cancer. Oncol Nurs Forum 1997; 24: $1403-8$.

[91] Pentheroudakis G, Pavlidis N. Cancer and pregnancy: poena magna, not anymore. Eur J Cancer 2006; 42: 126-40.

[92] Graham W, Newell ML. Seizing the opportunity: collaborative initiatives to reduce HIV and maternal mortality. Lancet 1999; 353: 836-9.

[93] Skinner EA. Perceived control, motivation, and coping. London: Sage Publications 1995. 
[94] Skinner EA. A guide to constructs of control. J Pers Soc Psychol 1996; 71: 549-70.

[95] Lobel M, Yali AM, Zhu W, DeVicent CJ, Meyer BA. Beneficial associations between optimistic disposition and emotional distress in high-risk pregnancy. Psychol Health 2002; 17: 77-95.

[96] Zafar AY, Alexander AC, Weinfurt KP, Schulman KA, Albernethy AP. Decision making and quality of life in the treatment of cancer: a review. Support Care Cancer 2009; 17: 117-27.

[97] Sherr L. Women and HIV. In: Citron K, Brouillette M, Beckett A, Eds. HIV and Psychiatry. 2nd ed. Cambridge: Cambridge University Press. 2005; pp. 217-35.

[98] Kiebert GM, Stiggelbout AM, Kievit J, Leer JW, van de Velde CJ, de Haes HJ. Choices in oncology: factors that influence patients' treatment preference. Qual Life Res 1994; 3: 175-82.

[99] Marly RC, Umezawa Y, Ratliff CT, Leake B. Racial/ethnic group differences in treatment decision-making and treatment received among older breast carcinoma patients. Cancer 2006; 106: 957-65.

[100] Prehn AW, Topol B, Stewart S, Glaser SL, O’Connor L, West DW. Differences in treatment patterns for localized breast carcinoma among Asian/Pacific islander women. Cancer 2002; 95: 2268-75.

[101] Canavarro MC. Gravidez e maternidade: representações e tarefas de desenvolvimento Pregnancy and parenting: representations and developmental tasks. In: Canavarro MC, Ed. Psicologia da gravidez e da maternidade Pregnancy and maternity's Psychology. Coimbra: Quarteto. 2001; pp. 17-48.

[102] Canavarro MC, Araújo-Pedrosa A. Transição para a parentalidade: compreensão segundo diferentes perspectivas teóricas Transition to parenthood: understanding according to different theoretical perspectives. In: Leal I, Ed. Psicologia da gravidez e da parentalidade Pregnancy and parenting Psychology. Lisboa: Fim de Século. 2005; pp. 22556.

[103] Taubman-Ben-Ari O, Shlomo SB, Sivan E, Dolizki M. The transition to motherhood: a time for growth. J Soc Clin Psychol 2009; 28: 943-70.

[104] Raphael-Leff J. Psychological processes of childbearing. London: Chapman \& Hall 1991.

[105] Sowden M, Sage N, Cockburn J. Coping and adjustment in pregnancy: giving babies a better start. In: Cockburn J, Pawson ME, Eds. Psychological challenges in obstetrics and gynecology: the clinical management. London: Springer. 2007; pp. 91-106.

[106] Salmela-Aro K, Nurmi J, Halmesmaki, T. Women's and men's personal goals during the transition to parenthood. J Fam Psychol 2000; 14: 171-86.

[107] Boss P. Family stress management: A contextual approach. London: Stage 2002.

[108] Vaz-Serra A. O stress na vida de todos os dias. Coimbra: Edição do Autor 1999.

[109] Nicolson P. Loss happiness and post-partum depression: the ultimate paradox. Can Psychol 1999; 40: $162-78$.

[110] King NMA, Chambers J, O’Donnell K, Jayaweera SR, Williamson C, Glover VA. Anxiety, depression and saliva cortisol in women with a medical disorder during pregnancy. Arch Womens Ment Health 2010; 13: 339-45.

[111] Cohen LJ, Slade A. The psychology and psychopathology of pregnancy: Reorganization and transformation. In: Zeanah CH, Ed. Handbook of infant mental health. 2nd ed. New York, London: Guilford Press. 2000; pp. 20-36.

[112] Nakano Y, Oshima M, Sugiura-Ogasawara M, Aoki K, Kitamura T, Furukawa TA. Psychosocial predictors of successful delivery after unexplained recurrent spontaneous abortions: a cohort study. Acta Psychiatr Scand 2004; 109: 440-6. 
[113] Hedegaard M, Henriksen TB, Secher NJ, Hatch C, Sabroe S. Do stressful life events affect duration of gestation and risk of preterm delivery? Epidemiology 1996; 7: 3339-45.

[114] Rondo PH, Ferreira RF, Nogueira F, Riberiro MC, Lobert H, Artes R. Maternal psychological stress and distress as predictors of low birth weight, prematurity, and intrauterine growth retardation. Eur J Clin Nutr 2003; 57: $266-72$.

[115] Sandman CA, Wadhwa PD, Chicz-DeMet A, Dunkel-Schetter C, Porto M. Maternal stress, HPA activity, and fetal/infant outcome. Ann N Y Acad Sci 1997; 24: 266-75.

[116] Sugiura-Ogasawara M, Furukawara TA, Nakano Y, Hori S, Aoki K, Kitamura T. Depression as a potential causal factor in subsequent miscarriage in recurrent spontaneous abortion. Hum Reprod 2002; 17: 2580-4.

[117] Talge NM, Neal C, Glover V, Early Stress Translational Research and Prevention Science Network: fetal and neonatal experience on child and adolescent mental health. Antenatal maternal stress and the long-term effects on child neurodevelopment: how and why? J Child Psychol Psychiatry 2007; 48: 245-61.

[118] Wadhwa PD. Psychoneuroendocrine processes in human pregnancy influence fetal development and health. Psychoneuroendocrinology 2005; 30: 724-43.

[119] McLearn KT, Minkovitz CS, Strobino DM, Marks E, Hou W. The timing of maternal depressive symptoms and mothers' parenting practices with young children: implications for pediatric practice. Pediatrics 2006; 118: $174-82$.

[120] Paulson JF, Dauber S, Leiferman JA. Individual and combined effects of postpartum depression in mothers and fathers on parenting behavior. Pediatrics 2006; 118: 659-68.

[121] Elmberger E, Bolund, C, Lützén K. Transforming the exhausting to energizing process of being a good parent in the face of cancer. Health Care Women Int 2000; 21: 485-99.

[122] Pedrosa CF. Resolução de problemas e percepção de controlo pessoal em indivíduos com comportamentos criminais recorrentes Problem solving and perception of personal control in individuals with recurrent criminal behavior. [Master's thesis]. Coimbra: University of Coimbra; 2003.

[123] Ponjaert-Kristoffersen I, Baetens P. Counselling patients with infertility problems. Int J Adv Counsell 1999; 21 : $246-61$.

[124] Altmaier E, Johnson B. Health-related applications of counseling psychology: Toward health promotion and disease prevention across the life span. In: Brown S, Lent R, Eds. Handbook of counseling psychology. New York: Jonh Wiley \& Sons. 1992; pp. 315-48.

[125] Avis NE, Crawford S, Manuel J. Psychosocial problems among younger women with breast cancer. Psychooncology 2004; 13: 295-308.

[126] Dunn J, Steginga SK. Young women's experience of breast cancer: defining young and identifying concerns. Psychooncology 2000; 9: 137-46.

[127] Schover LR. Sexuality and body image in younger women with breast cancer. J Natl Cancer Inst Monogr 1994: 177-82.

[128] Thewes B, Butow P, Girgis A, Pendlebury S. The psychosocial needs of breast cancer survivors: a qualitative study of the shared and unique needs of younger versus older survivors. Psychooncology 2004; 13: 177-89.

[129] Harvey J, Hobbie WL, Shaw S, Bottomley S. Providing quality care in childhood cancer survivorship: learning from the past, looking to the future. J Pediatr Oncol Nursing 1999; 16: 117-25.

[130] Semmens I, Saunders C, Puckridge P. A growing dilemma: breast cancer and pregnancy. Aust Fam Physician 2002; 31: 929-32.

[131] Churchill AC, Davis C. Realistic orientation and the transition to motherhood. J Soc Clin Psychol 2010; $29:$ 39-67. 
[132] Blackwell D, Elam S, Blackwell J. Cancer and pregnancy: a health care dilemma. J Obstet Gynecol Neonatal Nurs 2000; 29: 405-12.

[133] Girgis A, Sanson-Fisher RW. Breaking bad news: current best advice for clinicians. Behav Med 1998; 24 : $53-9$.

[134] Kraetschmer N, Sharpe N, Urowitz S, Deber RB. How does trust affect patient preferences for participation in decisionmaking? Health Expect 2004; 7: 317-26.

[135] Rogers C. Client-centered therapy. Boston: Houghton Mifflin 1951.

[136] Brown S J. Patient-Centered Communication. Annu Rev Nurs Res 1999; 17: 85-104.

[137] Girgis A, Sanson-Fisher RW. Breaking bad news: consensus guidelines for medical practitioners. J Clin Oncol 1995; 13: $2449-56$.

[138] Jenkins VA, Fallowfield LJ, Poole K. Are members of multidisciplinary teams in breast cancer aware of each other's informational roles? Qual Health Care 2001; 10: 70-5.

[139] Schmid Mast M, Kindlimann A, Langewitz W. Recipients' perspective on breaking bad news: how you put it really makes a difference. Patient Educ Couns 2005; 58: 244-51.

[140] Alaszewski A, Horlick-Jones T. How can doctors communicate information about risk more effectively? BMJ 2003; 327: 728-31.

[141] Edwards A. Communicating risks. BMJ 2003; 327: 691-2.

[142] Godolphin W. The role of risk communication in shared decision making. BMJ 2003; 327: 692-3.

[143] Paling J. Strategies to help patients understand risks. BMJ 2003; 327: 745-8. 